\title{
NATURALEZA ORGÁNICA Y RESPONSABILIDAD ÉTICA: HANS JONAS Y SUS CRÍTICOS ${ }^{1}$
}

\author{
Amán ROSALES RODRÍGUEZ²
}

- RESUMEN: En este trabajo se presentan y discuten algunos ejemplos de la recepción crítica a las ideas de Jonas, en especial las de carácter ético. Se enfatiza que la posición ética de Jonas no es una propuesta utópica o ingenua, sino realista y conciente de sus limitaciones. Algunos críticos olvidan que el "principio de responsabilidad" jonasiano está ligado a una recuperación del organismo libre, concebido como el centro de la reflexión ética.

- PALABRAS CLAVE: Tecnología, ciencia, ética, metafísica.

\section{Introducción}

Hans Jonas (1903-1993) dejó una obra filosófica importante y original, que apenas comienza a recibir en Ibero-América la atención que merece. Aunque ya se cuenta con varias traducciones castellanas de sus libros más significativos, su recepción crítica en el ámbito latinoamericano aún está por consolidarse. Por el contrario, en el campo internacional dicha reacción ha sido vasta, en especial en Alemania y Estados Unidos. El trabajo filosófico de Jonas cubrió áreas tan diversas

1 Este trabajo forma parte de un proyecto de investigación inscrito en la Escuela de Estudios Generales de la Universidad de Costa Rica.

2 Profesor en la Escuela de Filosofía y Escuela de Estudios Generales de la Universidad de Costa Rica. 
como la metafísica, la ética, la filosofía de la religión y la filosofía de la biología - o, como preferiría llamarla Jonas, la 'biología filosófica'.

Ahora bien, es interesante comprobar cómo, en lo que atañe al concepto más célebre acuñado por Hans Jonas, su "principio de responsabilidad" - en su obra principal del mismo nombre, El principio de responsabilidad. Ensayo de una ética para la civilización tecnológica, 1979 -, la respetuosa atención que ha merecido entre el público interesado por temas éticos y filosóficos contemporáneos, solo es comparable al volumen - igualmente revelador - de diversos intentos críticos que han buscado debilitar, e incluso 'eliminar' dicha expresión de las discusiones filosóficas del presente. Ello pone de manifiesto el cariz polémico de dicha noción y sus implicaciones filosóficas.

Pues bien, sería desde luego vano ensayar en este artículo un repaso siquiera muy incompleto de esa historia de recepción crítica del principio jonasiano de responsabilidad. El objetivo aquí perseguido es mucho más modesto aunque tal vez no exento de utilidad. Se trata de presentar algunas lecturas críticas - no necesariamente solo negativas - de la filosofía jonasiana en general y de su más reciente perspectiva ética en particular. Desde ellas se apunta, a veces con justificación, a diversas deficiencias de dichas ética y filosofía.

Sin entrar en una discusión pormenorizada de tales lecturas, en este articulo tampoco se ha dejado de señalar, cuando se ha creído oportuno, las concordancias o discrepancias con el contenido de cada crítica. En su mayoría toman posición frente a la afirmación cardinal de Jonas: "el mundo no está desprovisto de valores; en el mundo hay al menos un valor, la existencia de la responsabilidad, que es mejor que su no-existencia." (Jonas, 2001, pp. 71-2)

\section{Algunas interpretaciones de la filosofía de Jonas}

En un sugerente trabajo, W. Oelmüller (1988) ha procurado detectar lo que él percibe como una unidad entre los distintos momentos y temas del pensamiento de Jonas. En especial son tres los temas o problemas que conforman, en opinión de Oelmüller, y pese a su inicial - aparente - disparidad, la columna vertebral de la filosofía jonasiana: la búsqueda de un concepto creíble de Dios luego de la experiencia histórica de Auschwitz; la interpretación de la condición humana desde la perspectiva de la visión gnóstica de la realidad en conjunción con el análisis 'exis- 
tencial' heideggeriano, y, finalmente, la fundamentación, con base en el principio de responsabilidad, de una ética para el futuro de la civilización contemporánea.

Oelmüller plantea algunas dificultades, a su criterio inherentes, al intento jonasiano de fundamentar una nueva ética del deber basada no en una perspectiva antropocéntrica, sino respetuosa del ser de la naturaleza. Las importantes objeciones de dicho autor merecen ser consideradas. Ante todo llama la atención, acota Oelmüller, que Jonas diagnostique, de un lado, una suerte de bancarrota actual de la experiencia religiosa judeo-cristiana, y aún más de la posibilidad de que a partir de sus restos pueda todavía conformarse una ética a la altura de los problemas actuales.

Pero también, de otro lado, la propia propuesta ética de Jonas parece suponer - incluso por momentos también emplear - una base religiosa, sin la cual parece muy difícil, cuando no imposible, poner en práctica los estrictos lineamientos del "principio de responsabilidad". Nociones de fuerte tono religioso aparecen con frecuencia en una propuesta ética que supuestamente debe constituir un esfuerzo racional secular independiente de la experiencia religiosa - por ejemplo, nociones como las de veneración ("Ehrfurcht"), piedad ("Pietät"), y lo sagrado ("das Heilige"), entre otras.

Otro problema que Oelmüller encuentra en la propuesta ética jonasiana se refiere al tipo de fundamentación que cabría esperar de la naturaleza. Si ésta ya no se identifica con las antiguas nociones judeocristianas de un cosmos creado por un Dios providente, sino que es interpretada a la luz de las nuevas teorías evolucionistas y cosmológicas, mismas que han acentuado - según el propio Jonas - el sentimiento de soledad en el ser humano respecto a una naturaleza en sí indiferente a sus preocupaciones, ¿cómo es que Jonas propone también fundamentar una nueva ética - de carácter no-antropocéntrico - en el propio ser de la naturaleza?

Adicionalmente, Oelmüller plantea que el concepto jonasiano mismo de un hipostasiado "principio de responsabilidad" resulta más bien "contradictorio" con la demanda de responsabilidad ética al ser humano. Ese autor cree que en diversos ámbitos existe ya una importante conciencia de la necesidad de un actuar político y científico-tecnológico responsable - ética médica, ecología, investigación genética -, sin que sea necesario ahora fundamentar ontológicamente su implementación.

Hay algunos problemas en la interpretación sugerida por el interesante trabajo de Oelmüller, e.g. los siguientes: no hay una explicación 
clara de la línea de continuidad entre el tema de Dios después de Auschwitz con el de la relación entre el gnosticismo y el existencialismo. Esa línea de continuidad es importante y apunta a una dirección más o menos unitaria en la filosofía general de Jonas. A diferencia de las objeciones planteadas a su ética del futuro, no hay una discusión satisfactoria, siquiera brevemente señalada, de porqué el concepto jonasiano de Dios no es del todo verosímil. Tampoco queda claro porqué resulta tan claramente contradictorio el concepto jonasiano de responsabilidad, ni con qué base se sugiere su hipostatización de parte de Jonas.

Pero, en definitiva, pese a los reparos planteados, Oelmüller reconoce el aporte de Jonas a la filosofía contemporánea. Y es que sin preocuparse por las modas intelectuales, Jonas ha vuelto a poner, sobre la mesa de discusiones, una serie de problemas filosóficos importantes que de ningún modo estaban ya liquidados, como muchos creerían. Con las palabras de ese autor: "Si hoy en día judíos y cristianos, así como personas no religiosas, pero también científicos, economistas y políticos asumen y continúan estas discusiones, debe agradecérsele al amonestador y exhortador Hans Jonas" (Oelmüller, 1988, p. 351)

Por su parte, otro autor, Richard J. Bernstein no solo quiere exponer, sino también evaluar críticamente algunos de los principales componentes de la noción jonasiana de responsabilidad. Para empezar, Bernstein no halla convincente la insistencia de Jonas en tomar la relación padre-hijo como paradigma de responsabilidad. Jonas habría descuidado considerar la importancia de un sentido de responsabilidad mutua o recíproca entre las personas. Es de sobra conocido, históricamente hablando, el peligro de una concepción en exceso paternalista de la autoridad política.

Nadie niega el deber de los gobernantes de preocuparse por el bienestar de la comunidad, pero el problema es reducir, como Jonas, según Bernstein, lo hace, la noción de responsabilidad política al de una relación casi vertical entre padres e hijos. Fácilmente puede convertirse dicho paradigma en la práctica en una forma de abuso de autoridad, de parte de partidos o grupos que siempre presumirán de saber mejor que es lo mejor para la gente - se trata del peligro potencial del tecnocratismo.

En opinión de Bernstein, una responsabilidad 'vertical' como la sugerida por Jonas, fácilmente puede sucumbir a la tentación del elitismo de expertos, del conocimiento acaparado y aplicado por unos pocos privilegiados. Bernstein apunta, sin duda con razón que, incluso reconociendo la amplia noción jonasiana de la responsabilidad - e.g. su dimensión de futuro, que podría prevenir su uso autoritario en el presente 
-, lo cierto es que la inherente no-reciprocidad entre las personas pone en peligro el ámbito de la autonomía y capacidad decisoria individual.

Esa base presuntamente elitista de la ética jonasiana del principio de responsabilidad, deja mucho que desear según Bernstein:

Una adecuada explicación normativa de la política y la responsabilidad política debe reconocer también la centralidad de la responsabilidad recíproca mutua que puede (y debe) existir entre los participantes en una comunidad democrática política. (1994, p. 846).

Otra conocida objeción que ha menudo se le ha planteado a la ética jonasiana de la responsabilidad concierne al carácter encubiertamente antropocéntrico que, según algunos, se halla presente en su propuesta filosófica. En este sentido, Bernstein escribe acerca de una tensión irresoluta en el pensamiento de Jonas entre dos nociones de autoafirmación ontológica. De una parte, está su insistencia en basar su ética de la responsabilidad en el pilar ontológico de la propia vida orgánica. Mas luego pasa a extender ese sentido de autoafirmación orgánica general al ámbito mucho más restringido y complejo de la vida humana.

En varios lugares, acota Bernstein, Jonas escribe que el deber ético primario es la preservación de la vida humana, que la responsabilidad es un asunto básicamente de personas, y que hay una responsabilidad cósmica en resguardar la vida humana, pero el problema es que nunca queda enteramente claro "qué autoriza el paso del imperativo de preservar la vida orgánica a la más específica conclusión que el objetivo primario es preservar la existencia humana." (1994, p. 846)

¿Qué legitima considerar como primaria la tarea de salvaguardar a toda costa la vida de los agentes responsables del mundo - por encima incluso del resto de la vida orgánica? Bernstein señala en forma cáustica que de desaparecer la especie humana de la tierra, desaparecería también la amenaza mayor contra la preservación y continuación de la vida en el planeta. La observación de Bernstein es importante pero no fatal para la teoría ética jonasiana. Desde ésta se podría replicar que hay un deber especial en conservar la existencia de aquellos seres que son los únicos capaces de asumir responsabilidad por el efecto que sus actos puedan tener en el futuro.

La obligación suprema de conservar la vida humana no tendría entonces nada de antropocéntrico, sino que sería el único punto de partida posible para la admisión de cualquier otro tipo de responsabilidad hacia formas de vida no-humana. La autoafirmación de la vida misma 
es un hecho ontológico fundamental que logra superar, según Jonas, la famosa pero falsa distinción entre el ser y el deber-ser. El deber-ser ya estaría implícito, según él, en la 'iniciativa' asumida por la vida misma al proclamar su ser ante la incertidumbre y precariedad propias de la existencia orgánica.

Hay, aquí, sin embargo, apunta Bernstein, un vacío argumental importante en la teoría de Jonas. Pues parece necesario un argumento adicional que permita pasar de la premisa que hay una obligación suprema de preservar las condiciones para la posibilidad de la vida orgánica, a la conclusión que la existencia de la vida humana es un asunto primario o prioritario. Jonas no habría ofrecido un argumento independiente que establezca la validez de la anterior conclusión: "Uno necesita saber en qué sentido y por qué hay una prioridad ética de preservar la vida humana." (Bernstein, 1994, p. 848) Bernstein apunta con justificación que la propuesta jonasiana del "principio de responsabilidad" debe ser complementada con otros principios para que no se convierta en una propuesta noble pero vacua. Por ejemplo, se sugiere que habría que precisar mejor en qué sentido la ética de Jonas supera las éticas anteriores, 'meramente' antropocéntricas.

De hecho, ¿no se apropia el mismo Jonas de una gran cantidad de principios de éticas anteriores?, como apunta Bernstein: el reconocimiento de que todos los seres humanos son fines en sí mismos y que tenemos una responsabilidad mutua de tratar a nuestros congéneres con dignidad y respeto son principios que ya se encuentran incorporados en la mentalidad ética moderna (e.g., en Kant). Bernstein encuentra llamativo en el enfoque de Jonas cierto sentido de exageración e hipérbole al proclamar la necesidad de romper con éticas anteriores.

De nuevo, tales expresiones son desorientadoras porque hacen suponer una ruptura mayor con el pasado que la que Jonas realmente efectúa o se propone a fin de cuentas. Bernstein cree que el lenguaje altamente dramático de Jonas obedece a su deseo de llamar la atención sobre la nueva situación global que los cambios tecnológicos han traído consigo.

El mandato jonasiano de actuar de tal manera que los efectos de las acciones sean compatibles con al permanencia de vida humana genuina sobre el planeta es compatible, arguye, Bernstein, dada su extrema generalidad, con una gran cantidad de estrategias, algunas de las cuales el propio Jonas encontraría moralmente reprobables. Por ejemplo, el tolerar o fomentar hambrunas podría ser visto como una consecuencia 
más bien 'benévola', de aplicación del "principio de responsabilidad" de cara al futuro.

Igualmente, la continuación de una vida humana "digna", ¿no podría ser compatible con una estrategia de no-atención médica a cierto tipo de enfermos e incluso de ancianos? Todo lo anterior pondría de manifiesto que la sola máxima de Jonas a favor de la responsabilidad por el futuro de la vida sobre el planeta, no es suficiente para guiar las acciones de manera satisfactoria. Es claro que Jonas no aceptaría semejante estado de cosas incompatible con la 'dignidad intrínseca' del ser humano. El presente no puede ser sacrificado sin más al altar del futuro.

En todo caso, Bernstein parece llevar razón cuando señala que la perspectiva de Jonas no es muy clara al momento de precisar qué aspectos exactamente de la ética anterior deberían ser conservados en el nuevo enfoque de cara al futuro:

Así, cuando afirmo que la nueva ética de la responsabilidad de Jonas necesita ser complementada con una especificación de otros principios morales, estoy diciendo que necesitamos ser más cuidadosos y explícitos al especificar qué precisamente debe ser preservado y defendido en las varias formas de 'éticas tradicionales'. (1994, p 850)

Bernstein concluye que sus observaciones no han pretendido demostrar que Jonas está equivocado en todos sus planteamientos, sino solamente que es necesario mucho trabajo argumentativo adicional, a efecto de repensar y enriquecer, así como de hacer más viable la aplicación del valioso pero problemático "principio de responsabilidad.

Tratando de suavizar la objeción de Bernstein, otro intérprete, M. Werner, sugiere que la perspectiva jonasiana del "principio de responsabilidad" no pretende sustituir a todas las éticas del pasado, sino más bien complementarlas allí donde éstas fallan en tomar en consideración la magnitud (escala global) y gravedad (peligro real de autodestrucción). No deja de ser interesante cotejar dicha interpretación con la del propio Jonas y la insatisfacción que él manifiesta, sobre todo en El principio de responsabilidad, en torno a las limitaciones de las éticas tradicionales.

Pero, por otro lado, al no haber desarrollado Jonas un sistema de ética normativa en sentido estricto, Werner tiene razón al apuntar, indirectamente, que la posición de Jonas parece que al final desea complementar, antes que sustituir a las éticas anteriores. Si ello es así, entonces parece haber razón también en hablar de una ética jonasiana moderadamente antropocéntrica y cualificadamente presentista. 
De forma similar a lo sugerido por Bernstein, Werner acota que la idea jonasiana en el sentido de garantizar la permanencia de una vida humana auténtica sobre el planeta, permanece indeterminada, mientras no se especifique qué se quiere decir exactamente con lo de auténtica. El "principio de responsabilidad" jonasiano propone una manera muy general de valorar diversas situaciones anómalas del actual desarrollo científico-tecnológico, mas no es capaz, dada su misma generalidad e indeterminación, de ofrecer una orientación práctica más precisa respecto a situaciones específicas.

M. Werner menciona una de las objeciones típicas que se han presentado de cara a una de las formulaciones más conocidas del 'nuevo' imperativo categórico que Jonas hace explícito en El principio de responsabilidad: "Obra de tal modo que los efectos de tu acción sean compatibles con la permanencia de una vida humana auténtica en la Tierra." (Jonas, 1995, p. 40). Así formulado, el imperativo jonasiano deja sin definir, en efecto, a qué situaciones concretas puede y debe aplicarse. Pues: "No todo acto influye en las posibilidades de supervivencia de la humanidad." (Werner, 2003, p. 43).

W. E. Müller ha expuesto algunos reparos a la teoría ética jonasiana, en especial al concepto de responsabilidad, a la vez que reconoce la importancia de las contribuciones de Jonas para las discusiones actuales. Tales reparos pueden verse tanto en su libro de 1988 como, de modo más condensado, en un artículo del año 1989, justo el que será considerado a continuación. Contra las amenazas reales y potenciales de un desarrollo científico-tecnológico desbocado, Jonas cree que solo un vigoroso sentido de responsabilidad, ontológicamente fundado, puede tener el suficiente peso ético como para hacerle frente a dicho desarrollo.

El examen de Müller desea indagar hasta qué punto dicho imperativo resulta adecuado como instrumento para solucionar los problemas del presente. Para ello se muestran, primero, las afinidades de la reflexión de Jonas con las de Kant. Luego, la posibilidad de que se puedan ofrecer máximas éticas de acción para hacerle frente a un desarrollo científico-tecnológico creciente y acumulativo, que no parece admitir control de ningún tipo. En tercer lugar, Müller desea explorar el lugar de la teleología de lo viviente en el contexto de la filosofía de Jonas.

W. E. Müller opina que el análisis de Jonas pone en evidencia, con corrección, la primacía de lo antropocéntrico en el mundo moderno, éste se halla dominado por una obsesión de poner en práctica el "Programa baconiano" - así denominado por Jonas - de dominio científicotécnico sobre la realidad, mismo que en la época contemporánea esta- 
blece como una de sus prioridades lo que Hans Freyer llamara "la factibilidad de las cosas" ("die Machbarkeit der Sachen"), la obsesión por la manipulación absoluta de las cosas, así como su preparación para el consumo mundial.

Pero, apunta Müller, a pesar de las buenas intenciones de Jonas y de lo sugerente de su propuesta ética y metafísica, hay una conclusión de la que la teoría de Jonas no puede escapar:

la teleología natural (Naturteleologie) no puede ser entendida, sin embargo, en razón de su avasallamiento por la técnica - como lo hace, según Müller, Jonas -, como fuerza actuante de carácter autónomo, sino que indica la medida de la acción humana que debe ser percibida, a partir de la cual Jonas quiere superar los peligros del antropocentrismo. Pero en tanto que ideal, la teleología tiene una validez estructural supra-temporal. (Müller, 1989, p. 211)

¿Cómo puede entonces el intento de solución a los problemas del presente provenir tanto de 'dentro' - decisión autónoma de ejercer la responsabilidad - como de 'afuera' - movimiento teleológico de la vida en su conjunto a la permanencia en el ser?

Müller critica además de Jonas que éste no explique con mayor propiedad cómo es posible la derivación del deber ser a partir del ser. Por cierto que Müller confunde esta cuestión con la de la motivación que tendría que darse para que de la contemplación del ser se perciba la necesidad del deber ser y se actúe en consecuencia. Müller cree que Jonas no trata esa cuestión de la motivación precisamente porque ello significaría reconocer del todo la imposibilidad de que pueda darse en efecto dicha derivación.

En su lugar, Jonas propone la estrategia de la "heurística del temor" como un sustituto de derivación, pero eso no funciona como intento de fundamentación lógica. Müller cree que incluso Jonas cae en una contradicción: "la motivación para un actuar responsable de los seres humanos no puede ser implantada por la naturaleza de un lado, y por otro fundamentada y mediada lógicamente por medio de un principio, de un imperativo ontológico." (Müller, 1989, p. 212)

Todo lo anterior tiene que ver, estima Müller, con la posición de Jonas de cara al famoso principio de prioridad del ser frente a la nada. Pero la aceptación jonasiana de la prioridad del ser hace que su enfoque ético adquiera una estructura circular: "al ser le es inherente un valor, que por su parte fundamenta la prioridad del ser frente a la nada." (Müller, 1989, p. 212) Con ello, Jonas le da preferencia a la causa final en la 
determinación del comportamiento humano con la naturaleza. Pero la prioridad teleológica de la naturaleza no es suficiente, argumenta Müller, para apoyar el sentido de responsabilidad humana por la naturaleza: "pues precisamente la figura de la heurística del temor se basa en la comprensión del ser humano actuante autónomo, y su capacidad de poder pronosticar el futuro del ser y el deber ser." (P. 213) Pero esta posición, según Müller, no es lógicamente sostenible, pues el deber ser no puede apoyarse directamente en el ser, sino en otro elemento normativo independiente que le transmita al ser humano el sentido del deber respecto a la conservación del ser.

Como Jonas no proporciona ese otro principio adicional, su posición desemboca según Müller en un claro dilema: "La voluntad humana produce un deber ser incondicional y lo aplica en forma circular al querer." (Müller, 1989, 213) La objeción de Müller, que se basa en retomar viejas críticas a la dicotomía 'humeana' ser / deber ser, no es nueva ni necesariamente dañosa para Jonas. En la libertad humana culmina el largo proceso de formación de autoconciencia del universo o naturaleza. Ese mismo proceso, conducente a grados cada vez más amplios de conciencia de libertad el ser humano - como ya se dijo: punto culminante -, funge también como el medio que la naturaleza utiliza para autoprotegerse de la misma libertad que el ser humano representa.

La libertad de poder otorgar valor a la naturaleza no constituye simplemente un factor puesto desde fuera por una naturaleza providencial o por Dios, sino que forma parte de la propia capacidad intrínseca teleológica de la naturaleza. Se trata de la misma capacidad que le permite a la propia naturaleza - bajo la forma de lo orgánico - tanto tomar distancia de sí misma como ponerse como instancia legisladora, otorgadora de valores.

La conciencia de libertad no es pues un factor exógeno, interpuesto ad hoc por Jonas para apuntalar su teoría de la responsabilidad, sino que forma parte de lo que esa misma naturaleza - por definición - es y debe ser. Desde esta perspectiva, la otra objeción de Müller, en el sentido aproximadamente - que la responsabilidad humana, asumida como factor incondicional del deber, no puede sin embargo cumplir cabalmente dicho papel, pues ella misma forma parte del ser de la naturaleza, tampoco es fatal para los objetivos de Jonas. En el ser humano culmina, como se anotó, el largo proceso de toma gradual de conciencia de libertad que es al mismo tiempo toma gradual de conciencia de responsabilidad.

Las lecturas anteriores se han concentrado en señalar ciertas carencias o imprecisiones del enfoque ético jonasiano, pero no solo de ese 
tipo ha sido la recepción crítica de dicho enfoque. Otro autor ha señalado con acierto que uno de los principales aporte de Jonas consistió en oponerse a la idea de que existen ciertas coacciones objetivas ("Sachzwänge") inapelables, que pueden servir de excusa, por ejemplo, para la inactividad política. (Cf. Schütze, 1995, p. 41). Hans Jonas, en efecto, pese a destacar la magnitud de la empresa científico-tecnológica en la que está comprometido el ser humano contemporáneo - indicación que lo lleva incluso a un acercamiento con posiciones de aceptación fuerte del determinismo tecnológico -, en ningún momento claudica en su idea de que es el mismo ser humano - no la Ciencia o la Tecnología, pero tampoco Dios o la Historia - el único responsable por la marcha de los acontecimientos y por el cariz futuro de la historia. (Cf. sobre el tema, Rosales R., 1999)

Así, resulta interesante comprobar cómo el repudio jonasiano de las coacciones objetivas es coherente con su polémica interpretación de la relación entre Dios y el ser humano. En dicha relación Dios está ausente como fuerza causal activa - su papel primario fue de servir como motor de impulso en la creación de un universo auto-evolvente. Pero el deus otiousus de Jonas no es, sin embargo, un Dios indiferente a las vicisitudes del mundo por Él creado, lo que sucede es que su no-omnipotencia le constriñe a mantenerse al margen de un proceso de creación continuada por la que solo el propio ser humano es ahora responsable. (Cf. sobre el problema de Dios en Jonas, Rosales R., 2003)

La teoría ética jonasiana concibe al ser humano como una suerte de custodio de una Creación que él en principio no creó, pero que sí se mantiene gracias a su intervención en los procesos que ocurren en su interior. En su conjunto, esta forma de visualizar la posición del ser humano respecto a la naturaleza destaca un importante sentido de unidad en la filosofía de Jonas, es decir, en lo que atañe a los grandes temas que se mantienen en el centro de sus reflexiones filosóficas. Todo lo cual podría resumirse, siguiendo en parte la exposición de Schütze, aproximadamente de la siguiente forma.

La responsabilidad humana absoluta por lo que acaece en este insignificante planeta es concordante con el hecho de la 'inactividad' actual de Dios. Pero, de dónde surge entonces la obligación humana por obrar en forma responsable? No de Dios, claro está, sino de la propia naturaleza y los fines intrínsecos que pueden entreverse de sus procesos. La incipiente autoafirmación de la vida orgánica que persiste luego en su ser, es una clara muestra, de nuevo, a los ojos de Jonas, de que el abismo entre el ser y el deber ser no es más que una - peligrosa - inven- 
ción humana. La biología filosófica, pensada por Jonas, enfatiza la interacción entre la naturaleza orgánica metabolizante y su entorno natural, y complementa ideas e intuiciones tanto de su teología especulativa como de su ética de la responsabilidad.

El apartarse obligado de Dios - en razón de su no-omnipotencia de la Creación no implica en absoluto para Jonas que ahora todo esté permitido al ser humano. Al contrario, con esta situación, el grado de responsabilidad se acrecienta, fundamentándose en el propio mandato de la naturaleza de mantener incólume la existencia de la vida. En esa medida, la ciencia y la tecnología se convierten en los únicos medios tal vez - conque cuenta la humanidad para tratar de enmendar los desaciertos que ella misma ha ocasionado con su uso imprudente. La creatividad tecnológica, consustancial al ser humano (homo faber), debe ser utilizada adecuadamente, no desechada, para tratar de corregir los abusos del poder humano.

En razón de la difícil, cuando no imposible tarea de constituir una ligazón religiosa a la altura de las circunstancias actuales, Jonas insiste en la necesidad de volver la mirada ya no a la trascendencia, sino a la más cercana inmanencia de un "principio de responsabilidad" que goza de una fuerza de inmediatez tal que resulta imposible no ser advertido de su presencia o no sentirse comprometido con su implementación por medios políticos. Para Jonas: "En el tanto que el ser humano es capaz de sentir responsabilidad la tiene, y en consecuencia él es responsable por la existencia ulterior de aquello que existe" (Schütze, 1995, p. 41).

El problema, obviamente, es que a pesar de que en todo lo anterior Jonas pueda llevar razón, el reconocimiento de la existencia de un cierto reino de los fines consustancial a la vida misma, no pareciera suficiente para mover la ejecución de políticas drásticas de verdadera protección a gran escala de la vida sobre el planeta. Con todo, Jonas combate con firmeza la fatal idea del àpres nous le deluge. De hecho, más a que ningún otro autor reciente, a Jonas se debe, apunta con razón Schütze, el renacimiento de las discusiones sobre ética aplicada en el mundo angloparlante de la segunda mitad del sigo veinte, dominada más bien por el análisis filosófico, por diversas teorías logicistas de la ciencia, así como relativismos diversos y más recientemente, también variopintos postmodernismos. Haciendo caso omiso de modas filosóficas e intelectuales, indiferente al tipo de simpatía o antipatía política que sus reflexiones pudiesen generar, Jonas se ganó la reputación de ser un pensador íntegro y sincero ante todo consigo mismo. 
Por otra parte, un aspecto que llama mucho la atención de la carrera intelectual de Jonas es el hecho de que en ella convergen una serie de temas y problemas normalmente tratados en forma independiente por otros filósofos o teólogos. Así, por ejemplo, el interés temprano de Jonas por la religión gnóstica y por su particular visión de la realidad, interés que fue alimentado por la filosofía 'existencial' de Heidegger, reaparece bajo la forma de una dura crítica a la mentalidad científico-tecnológica moderna, nutrida de ciertos ingredientes gnóstico-dualistas que insisten en el antagonismo entre el ser humano y una naturaleza que le es ajena.

Lo anterior se desarrolla a cabalidad en un importante texto jonasiano, original de los años cincuenta del siglo pasado, "Gnosticismo, nihilismo y existencialismo". Este texto, a su vez, que en principio solo plantea el diagnóstico de una modernidad subdeterminada por dañosas influencias gnósticas y nihilistas modernas (como el propio existencialismo) habrá de ser complementado más de dos décadas después por la propuesta terapéutica ética concreta, que Jonas elabora durante la década de los setenta con vistas a enfrentar los efectos actuales de la herencia gnóstico-nihilista. (Cf. sobre ese desarrollo, Rosales R., 2001)

Pero además del llamamiento jonasiano por ejercer en forma incondicional el "principio de responsabilidad," otros dos temas - de nuevo aparentemente inconexos con los ya indicados - complementan la perspectiva filosófica general de su autor. Por un lado, la biología filosófica de su autor es un intento por combatir y sustituir el viejo dualismo mente-cuerpo mediante una apelación al papel desempeñado por una visión integral de la existencia humana, visión que para Jonas culmina en la noción de 'organismo'. Por otro lado, además del esbozo de un cierto monismo psicofísico, Jonas retoma su viejo interés por temas religiosos en las distintas formulaciones que realiza de su polémico mito del Dios sufriente y en devenir.

Los temas de Dios y lo divino, el de la naturaleza viviente, y el del necesario marco ético para tratar con dicha naturaleza, son temas capitales del pensamiento jonasiano que además, vistos de cerca, guardan entre sí una sugerente trabazón y otorgan unidad a la creación filosófica jonasiana. Dicha unidad está siempre presente, si bien requiere un esfuerzo de reconstrucción a partir de los primeros momentos de la filosofía de Jonas.

\section{Conclusión}

En la obra principal de Jonas, El principio de responsabilidad, se hace patente la necesidad de elaborar un concepto filosóficamente 'rea- 
lista', no utópico, de responsabilidad. Dicha elaboración tiene que tomar en cuenta la imposibilidad de ofrecer panaceas de éxito garantizado para los problemas. Dos aspectos finales, característicos de la teoría filosófica de Jonas, merecen ser subrayados.

Por una parte, resulta notable el sentido de modestia y la conciencia de la propia falibilidad inherentes a la ética jonasiana. Dicha actitud se refleja con claridad en el siguiente pasaje:

Una cosa debemos tener por fin clara: una solución patentada para nuestro problema, un remedio universal a nuestra enfermedad, no existe. Para algo así, el síndrome tecnológico es demasiado complejo, y en una renuncia no cabe ni soñar. Incluso con una gran 'inversión de la marcha' y una reforma de nuestras costumbres, el problema fundamental no desaparecería. Puesto que la aventura tecnológica misma debe continuar su camino; incluso las rectificaciones salvadoras requieren siempre una nueva aplicación del ingenio técnico y científico, que genera sus propios riesgos nuevos. La misión de evitar es, pues, permanente, y su cumplimiento no debe ser nunca más que un remiendo y, a menudo, incluso no más que una chapucería.. (Jonas, 2001, p. 132)

Por otra parte, es primordial entender la relación que mantienen las nociones de 'libertad', 'organismo' y 'responsabilidad' en la filosofía de Jonas, relación que varios de sus críticos no parecen captar bien o en toda su magnitud. Si la libertad es un ingrediente fundamental, implícito en el equipamiento natural de ciertos organismos, el sentido de responsabilidad, compañero inseparable de la primera, ha de considerarse también ingrediente esencial, con el que se complementa la díada organismo y libertad con el tercer concepto jonasiano central de la responsabilidad - y su concomitante, el de deber. Otra forma de explicitar dicha relación de configuración naturalista-teleológica, la ofrece el propio Jonas en el curso de una de sus entrevistas. Con sus palabras se cierra también este trabajo:

Nuestros cerebros, como otros sistemas orgánicos, están constituidos de tal forma que inventan por sí mismos valores. Por ejemplo, se abrazan a su propio ser, libran la lucha por la supervivencia, la cual es un valor (...) En tanto y cuanto el hombre es el único ser conocido que puede tener responsabilidad, por ello, justamente, la tiene. (...) Resulta, pues, que, a través de una inferencia propiamente ontológica, el mero hecho de que podamos tener responsabilidad hace que esta responsabilidad sea prescripción de su propia supervivencia en este mundo. (Jonas, 2001, pp. 71-2) 
RODRÍGUEZ, A. R. Organic nature and ethical responsability: Hans Jonas and his critics. Trans/Form/Ação, (São Paulo), v.27 (2), p.97-111, 2004.

- ABSTRACT: In this paper, a few examples of the critical reception of Hans Jonas' ideas are presented and discussed. It is emphasized that Jonas' ethical position it is not a naïve or utopian proposal, but realistic and aware of its limitations. Some critics forget that the Jonasian "principle of responsibility" is linked to a recovery of the free organism as the center of ethical reflection.

- KEYWORDS: Technology, science, ethics, metaphysics.

\section{Referencias bibliográficas}

BERNSTEIN, R. J. "Rethinking Responsibility", Social Research, Vol. 61 (4), p. 833-852, 1994.

JONAS, H. Más cerca del perverso fin y otros diálogos y ensayos. Madrid: Los Libros de la Catarata, 2001.

El principio de responsabilidad. Ensayo de una ética para la civilización tecnológica. Barcelona: Herder, 1995.

MÜLLER, W. E. "Zur Problematik der Verantwortungsbegriffes bei Hans Jonas", Zeitschrift für evangelische Ethik, Vol. 33, p. 204-216, 1989.

Der Begriff der Verantwortung bei Hans Jonas. Frankfurt a. M.: Athenäum, 1988.

OELMÜLLER, W. "Hans Jonas. Mythos - Gnosis - Prinzip Verantwortung", Stimmen der Zeit, V (206), p. 343-351, 1988.

ROSALES RODRÍGUEZ, A. "Hans Jonas, 'El concepto de Dios después de Auschwitz' y su relación con la idea de un pensamiento posmetafísico", Areté, XV (2), p. 267-302, 2003.

"Nihilismo y tecnología: Hans Jonas y la filosofía de la historia", Sapientia, LVI (209), p. 213-235, 2001.

"Hans Jonas y el determinismo tecnológico", Revista de Filosofía de la Universidad de Costa Rica, XXXVII (93), p. 313-320, 1999.

SCHÜTZE, Ch. "The Political and Intellectual Influence of Hans Jonas", The Legacy of Hans Jonas, Hastings Center Report, Vol. 25, N. 7, p. 40-44, 1995.

WERNER, M. H. "Hans Jonas 'Prinzip Verantwortung'”. En: Düwell, M., K. Steigleder, Hrsg., Bioethik. Eine Einführung. Frankfurt a. M.: Suhrkamp, 2003, p. 41-56. 